\title{
Effect of Sludge Residence Time over Anaerobic Biodegradation of High Saline Biomass
}

\author{
Tareq W. M. Amen*†, Meng Sun*, Mitsuharu Terashima* and Hidenari Yasui* \\ Faculty of Environmental Engineering, The University of Kitakyushu, Hibikino 1-1, Wakamatsu-ku, Kitakyushu-shi, \\ Fukuoka 808-0135, Japan \\ †Corresponding author: Tareq W. M. Amen; t-amen@kitakyu-u.ac.jp; eng.twa@gmail.com
}

Nat. Env. \& Poll. Tech.

Website: www.neptjournal.com

Received: 30-07-2021

Revised: 02-09-2021

Accepted: 11-09-2021

Key Words:

Halophytes

Anaerobic digestion

Methane generation

Salt-tolerant biomass

\begin{abstract}
Halophytes are unique in that they can thrive in a wide range of soil conditions, from normal to extremely saline. This has recently prompted researchers to consider using halophytes as a phytoremediation end-product as a source for biogas generation. Therefore, applying the anaerobic digestion process for halophytes may have the potential advantage in terms of efficient land utilization, soil remediation, and biogas production. Based on this, the anaerobic digestion efficiency of high saline biomass was investigated in continuous laboratory-scale anaerobic reactors at two different sludge residence times (SRT) of 40 and 80 days. Under mesophilic atmosphere, two reactors were operated, one reactor used organic substrate with $30 \mathrm{~g}-\mathrm{Na}^{+} \cdot \mathrm{L}^{-1}$ originating from sodium chloride whereas the other was operated with the presence of sodium bicarbonate and sodium sulfate. The salt-tolerant microorganism was gradually developed and the salt concentrations were selected based on the elemental analyses results of 30 species of wild halophyte plants taken from the saline-affected area of the Aral Sea in Uzbekistan during the early phase of the operation. For 40 and 80 days of SRT, respectively, 65.56 percent and 60.42 percent of the feed COD were converted into methane gas by the chloride system. However, only about $60 \%$ of the feed COD was converted into methane for bicarbonate, and the remaining fraction of gas was assigned to sulfide as a final product of increased sulfate reduction bacteria activity. These findings showed that the salt-tolerant microorganism could be incubated and the anaerobic digestion process could be adapted for a high-saline substrate, implying that the biodegradability of phytoremediation end-products may be used for methane production.
\end{abstract}

\section{INTRODUCTION}

Because of urbanization and the increasing worldwide population, arable land is decreasing. Soil salinity is one of the most serious environmental factors limiting agricultural crop productivity and the quality of crops. Because most ordinary crops are salt sensitive, salinity affects a large percentage of agricultural fields, making conventional agriculture ineffective. Several practical measures, including soil washing and irrigation control, are now being used to restore the affected lands (Toderich et al. 2009). Moreover, a biological engineering solution called phytoremediation using halophyte plants is a promising approach to reform the salinized lands.

Halophytes are distinguished as they can flourish well in soils ranging from normal to severely saline conditions and it can offer an interesting alternative feedstock for the process of biogas production. Consequently, anaerobic digestion of residual phytoremediated biomass provides the ability to produce methane which can be used as electrical and thermal energy.
It is anticipated that the integration of anaerobic digestion of phytoremediated biomass in biogas production will become an environmentally sustainable and economically feasible solution in terms of renewable energy and saving resources. Applying anaerobic digestion under saline conditions is an appropriate process for integration into halophytes biogas production and/or salts recovery, and is of utmost importance for increasing the feasibility of the phytoremediation technologies.

The use of halophytes as a substrate for anaerobic digestion presents at least two distinct challenges. The first is the physico-chemical characteristics of the halophytes biomass as a substrate feedstock for anaerobic digestion, which will determine the biodegradable portion of the biomass, and the second is the high salinity associated with halophytic culture conditions, which will determine the biodegradable portion of the biomass. Lefebvre et al. (2007) and Margesin \& Schinner (2001) both concluded the potentials of adaptation of salt-tolerant microorganisms in anaerobic treatment processes under saline conditions because a high diversity 
could be maintained in an anaerobic reactor despite the increase in $\mathrm{NaCl}$ concentration.

However, according to Wood (2015), excessive saline concentrations cause dehydration and plasmolysis because of the osmotic pressure across the microbial cell membrane. Clearly, the ability of microbial communities to live in a wide range of salinities expands the possibilities for anaerobic digestion applications for phytoremediated biomass, allowing the process to gradually recover its efficiency (Luo et al. 2016). Sierra et al. (2018) found that the proliferation of salt-tolerant microorganisms resulted in an enduring microbial community, which increased the process performance robustness over a wide range of sodium concentrations.

Therefore, further research is required to build up the understanding of the successful application of anaerobic digestion under high saline conditions. Based on that, this study aims to evaluate the bioconversion performance and material balance fractionations in the continuous operation of anaerobic bioreactors that are carried out with the addition of different salt sources at different sludge ages. Two reactors were operated and the sludge retention time (SRT) was changed through the course of operation, one reactor used organic substrate with high sodium chloride concentration whereas the other was operated with the presence of sodium bicarbonate and sodium sulfate.

\section{MATERIALS AND METHODS}

\section{Bioreactor Set-Up and Operation}

At the initial phase, two lab-scale anaerobic tank reactors with a 4-L working volume namely chloride system and bicarbonate system were continuously operated with daily feeding. The reactors were constantly mixed by regular stirring, which was controlled by an electrical motor attached to the reactor. Over the course of the experiment, both reactors were started, filling the working volume with a fresh inoculum in a chemostat mode at $35^{\circ} \mathrm{C}$ and neutral $\mathrm{pH}$. Fresh inoculum sludge was taken from a full-scale experiment anaerobic digester treating municipal sewage at Kitakyushu's Hiagari sewage treatment plant (STP) and was sieved through a $2.3 \mathrm{~mm}$ screen before use.

No additional alkalinity, or buffer, was introduced into the inoculum. Whereas the artificial halophytes were formed using fodder plant of Panicum coloratum which was used as the substrate from the beginning of the experiment. To facilitate injection of the substrate into the systems, the fodder plants were ground into fine particles using a blender and then mixed with targeted salt concentrations as listed in Table 1. The substrate was manually fed once a day using a $100 \mathrm{~mL}$ plastic syringe. The experiments were started with an acclimation period were started with a low organic loading rate (OLR), then the OLR was carefully and gradually increased until $2.0 \mathrm{~g}-\mathrm{COD} / \mathrm{L} / \mathrm{day}$. The two reactors then were subjected to two different SRTs of 40 and 80 days.

At a predetermined time, samples were taken from each reactor and directly were separated using a centrifugal solid/ liquid separation unit. Then, the supernatant was used to measure the soluble organic content and the settled pellets were used to measure the particulate organic fraction besides retaining the reactors to ensure the operated SRT. Methane gas production was continuously logged using a gas counter (MGC-1, Litre Meter Limited, UK) after passing it through caustic pellets to remove $\mathrm{CO}_{2}$ in the biogas. The produced methane volume was corrected to standard pressure and temperature.

\section{Process and Physicochemical Analyses}

The obtained supernatant was filtered using a glass filter (Whatman GF/F) then the soluble COD concentrations were calculated based on the soluble TOC measurements and

Table 1: Influent composition of $1 \mathrm{~kg}$ for the chloride and bicarbonate substrates.

\begin{tabular}{|c|c|c|c|c|}
\hline & & Chloride System & Bicarbonate System & Unit \\
\hline \multicolumn{2}{|l|}{$\mathrm{NaCl}$} & 76.27 & - & g.kg-1 \\
\hline \multicolumn{2}{|l|}{$\mathrm{Na}_{2} \mathrm{SO}_{4}$} & - & 29.57 & g. $\mathrm{kg}^{-1}$ \\
\hline \multicolumn{2}{|l|}{$\mathrm{NaHCO}_{3}$} & - & 74.645 & g. $\mathrm{kg}^{-1}$ \\
\hline \multicolumn{2}{|c|}{$\mathrm{FeCl}_{2} \times 4 \mathrm{H}_{2} \mathrm{O}$} & & 17.49 & g. $\mathrm{kg}^{-1}$ \\
\hline \multicolumn{2}{|l|}{$\mathrm{H}_{2} \mathrm{O}$} & 873.73 & 721.45 & g. $\mathrm{kg}^{-1}$ \\
\hline \multicolumn{2}{|c|}{ Organic - Panicum coloratum - } & 44 & 44 & $\mathrm{~g}$-VSS.L $\mathrm{L}^{-1}$ \\
\hline \multirow[t]{3}{*}{ Crude fiber } & Hemicellulose & 212.77 & g.kg-DM ${ }^{-1}$ & g.kg-DM ${ }^{-1}$ \\
\hline & Cellulose & 328.42 & g.kg-DM ${ }^{-1}$ & g.kg-DM ${ }^{-1}$ \\
\hline & Lignin & 64.42 & g.kg-DM ${ }^{-1}$ & g.kg-DM ${ }^{-1}$ \\
\hline
\end{tabular}


the soluble COD/TOC factor whereas the particulate COD concentrations were calculated based on the ratio of COD/ VSS and measurements of VSS based on \#2540 in Standard Methods (APHA, 2005) and. Volatile fatty acids (VFA) concentrations were measured using an ion chromatography system (Dionex ICS 1000) with Pac AS11-HC column, Thermo Fisher Scientific Inc., USA.

The feedstock plant was characterized for both volatile solids and ash content based on calculating the differences between the suspended solids content and the ash content. The suspended solid was determined by drying the samples at $105^{\circ} \mathrm{C}$ for $24 \mathrm{~h}$ to ensure a constant weight, where the ash content was determined after using the oven-dried samples and placed in pre-weighted ceramic crucibles and then ignited for $2 \mathrm{~h}$ at $550{ }^{\circ} \mathrm{C}$ in a muffle furnace.

The structural composition and the fiber components of fodder plant powders were determined based on AOAC (Chemists \& Horwitz 1975). The cellulose, hemi-cellulose, and lignin fraction were calculated based on the measurements of neutral detergent fiber (NDF), acid detergent fiber (ADF), and acid detergent lignin (ADL) as detailed by Segura-Campos et al. (2014). Prior to analysis, all data was validated for homogeneity of variance.

The evaluation of the ultimate amount of methane produced under anaerobic conditions $\left(\mathrm{mL} \mathrm{CH}_{4} \cdot \mathrm{g}^{-1} \mathrm{COD}\right)$ is crucial to predict the performance of the anaerobic digestion process (Kianmehr et al. 2014). Therefore, the efficiency of the anaerobic digestion process was mainly calculated in terms of biodegradability percentage (1) (Mottet et al. 2009).

$\%$ Biodegradation $=\frac{\text { Produced Methane }}{\text { Potential Methane }} \cdot 100 \%$

where the potential methane is theoretically calculated under the reactor's operation conditions as $0.35 \mathrm{~L}$ of methane gas can be generated for each $1 \mathrm{~g}$ of COD under normal conditions, and the produced methane is the generated methane from each reactor that is directly related to the degradation of the substrate. (273.15 K and $101.325 \mathrm{kPa}$ ).

Biochemical methane potential (BMP) experiments based on anaerobic respirometric batch tests employing respirometric apparatus (Challenging Systems Inc., USA (AER-8)) were used as COD fractionation assays to determine the proportion of soluble COD retained in reactor conversion. $500 \mathrm{~mL}$ glass bottles were used as reactors and then each reactor was filled with $400 \mathrm{~mL}$ of inoculum. To ensure only methane gas will be recorded and the $\mathrm{CO}_{2}$ will be absorbed, caustic material was placed between the sensing device and the temperature-controlled incubator.

The soluble substrate of the two reactors was used as a substrate. The tests were anaerobically incubated at $35 \mathrm{C}$ after tightly being closed. The net generated methane volumes were calculated based on the Gay-Lussac law and then normalized to the volume of gas under normal conditions. Additionally, the theoretical methane production potential of biomass residues used in this study was calculated based on the ratio between the VS and COD, considering the operation conditions of the respirometer as temperature and pressure.

The fraction of COD converted into methane can be measured by monitoring the methane production rate, and the inert fraction of COD was calculated by equation (2).

$\mathrm{COD}_{\mathrm{I}}=\mathrm{COD}_{\mathrm{T}}$ - Produced $\mathrm{CH}_{4}$

where, $\mathrm{COD}_{\mathrm{I}}$ is the inert $\mathrm{COD}, \mathrm{COD}_{\mathrm{T}}$ is the total $\mathrm{COD}$ initially introduced substrate.

\section{RESULTS AND DISCUSSION}

\section{Inoculum and Substrate Basic Composition}

Table 2 presents the average basic proximate and structural characteristics of the inoculum and substrate composition. The particulate composition of fodder plant which is used as the organic substrate mainly consists of cellulose and hemi-

Table 2: Inoculum and the influent feed basic proximate and structural characteristics.

\begin{tabular}{|llll|}
\hline & Seeding Sludge [Inoculum] & Fodder Plant [Substrate] & Unit \\
\hline Origin & Hiagari STP & Panicum coloratum & - \\
\hline VSS & 16.87 & 47.27 & g-VSS.L ${ }^{-1}$ \\
Ash & 26.33 & 5.47 & wt.\% \\
Cellulose & 71.12 & 328.42 & g.kg-DM \\
Hemi cellulose & 241.28 & 212.77 & g.kg-DM-1 \\
Lignin & 367.19 & 64.42 & g.kg-DM ${ }^{-1}$ \\
Lipid & N.A. & 12.86 & g.kg-DM ${ }^{-1}$ \\
Protein & N.A. & 73.06 & g.kg-DM \\
\hline
\end{tabular}


cellulose which reflects the substrate potential for anaerobic digestion process since it would release a high amount of intermediates which eventually will be consumed by different strains of methanogens.

The dried mass (DM) of the fodder plant residues was found to include $328.42,212.77$, and $64.42\left(\mathrm{~g} . \mathrm{kg}-\mathrm{DM}^{-1}\right)$ of cellulose, hemicellulose, and lignin, respectively. The presence of lignin in the substrate will prevent cellulose from being degraded by enzymes since it can act as a coating material to protect cellulose

\section{Effect of Sludge Retention Time}

Initially, the methane production rate was gradually increased in accordance with the expected methane production rate by increasing the OLR. Experimentally, at the initial phase of incubation, the VFAs were detected and as the process progressed, the VFAs decreased and were maintained under the inhibition level as a consequence of methanogens adaptation and its subsequent methane generation (Fig. 1). Consequently, the methane generation rate increased until achieving a steady state.

Both reactors were run on a 40-day SRT before being switched to an 80-day SRT to promote the low-activity-rate microorganisms involved in salt-tolerant biomass degradation. As these salt-tolerant microorganisms grew bigger, more substrate hydrolysis activities occurred, and the rate of methane conversion increased.
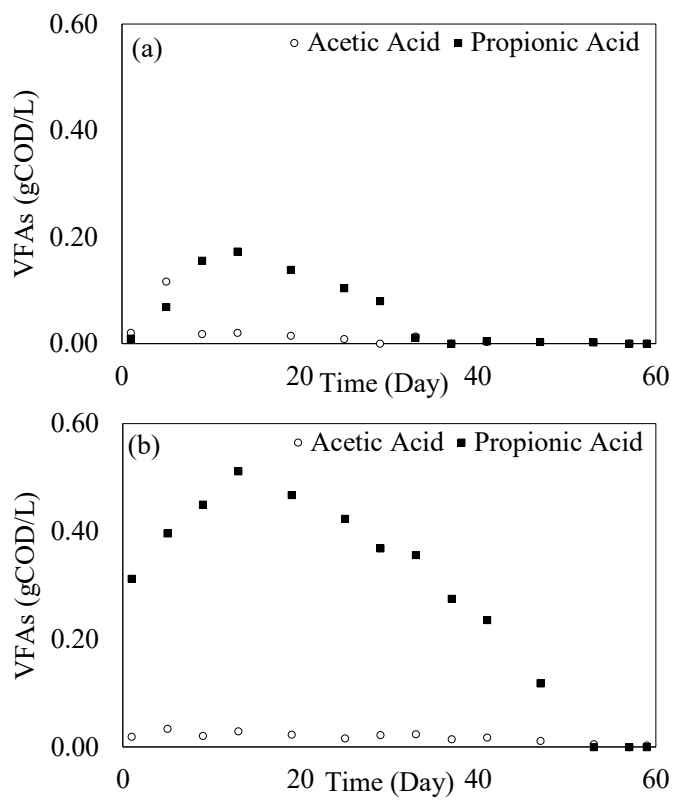

Fig. 1: The VFAs concentrations at the accumulation phase for (a) chloride reactor and (b) bicarbonate reactor.
Once the systems have reached a steady state, the increasing trend of particulate COD, particularly for the chloride system, is not readily visible, indicating that the biodegradability has improved as the SRT increased. In contrast, the particulate concentration in the bicarbonate system still has an increasing trend.

The soluble COD concertation for chloride and bicarbonate systems was in the range of $1.35 \mathrm{~g}-\mathrm{COD} . \mathrm{L}^{-1}$ to $3.15 \mathrm{~g}$-COD.L $\mathrm{L}^{-1}$ and $1.36 \mathrm{~g}-\mathrm{COD} . \mathrm{L}^{-1}$ to $2.10 \mathrm{~g}$-COD.L $\mathrm{L}^{-1}$, respectively (Fig. 2). Soluble COD signals the hydrolysis conversion of plant biomass lignocellulosic components into fermentable intermediates that will eventually contribute to methane generation (Gallipoli et al. 2014).

Likewise, the variation in soluble and particulate COD for anaerobic digestion process for both chloride and bicarbonate systems, the produced methane for two systems, are presented in Fig. 3

The time course evaluation for the two reactors was observed based on comparing the mass balance outcomes in terms of produced methane percentage that was lost to the atmosphere, soluble COD lost with effluent, and the particulate COD in the reactor as shown in Fig. 4. The anaerobic digestion shows a stable production rate of methane for both SRT at 40 and 80 days. When we compare Fig. 4(a), (b) with Fig. 4(c), (d), we can see that this is the case for both the particulate and soluble fractions of COD.
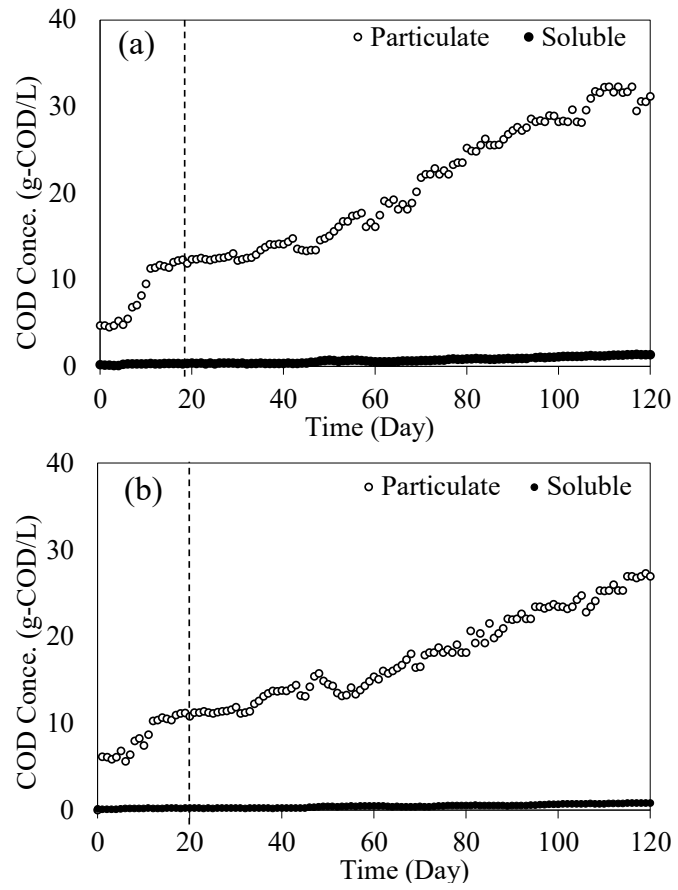

Fig. 2: Measured soluble, and particulate COD for (a) chloride system and (b) bicarbonate system. 
In terms of the efficiency of anaerobic digestion processes, more than $60 \%$ of the feed substrate was converted to a gas phase which means it is possible to get high methane production from artificial halophytes and this outcome is in the agreement with Ras et al. (2011) who achieved 51\% of COD conversion to methane under SRT of 28 days. This result is also in line with Sierra et al. (2018) who showed that a short-term continuous fluctuation between 18 and 20

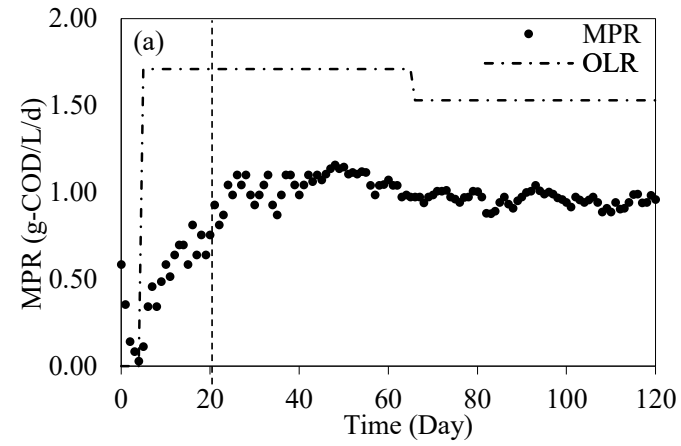

$\mathrm{g}-\mathrm{Na}^{+} \cdot \mathrm{L}^{-1}$ eventually has no impact on the bioconversion anymore after a long-term operation, suggesting a successful gradual adaptation to higher sodium concentrations.

\section{Conversion Rate at Steady State}

The steady-state outcomes for the chloride system for both 40 and 80 days of SRT showed 65.56 percent and 60.42 percent of the feed COD was converted in methane

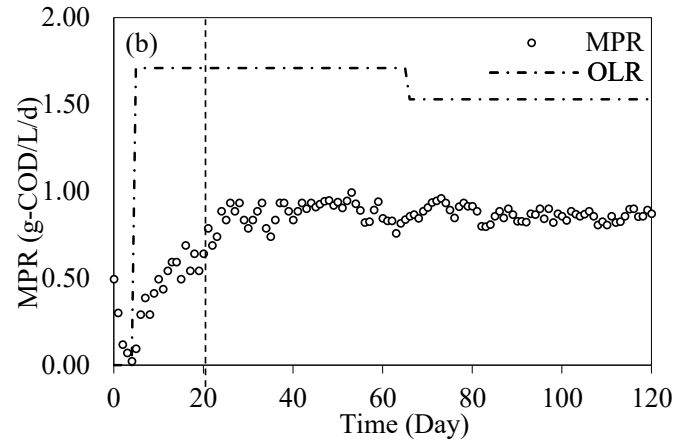

Fig. 3: Methane produced rate for (a) chloride system and (b) bicarbonate system.
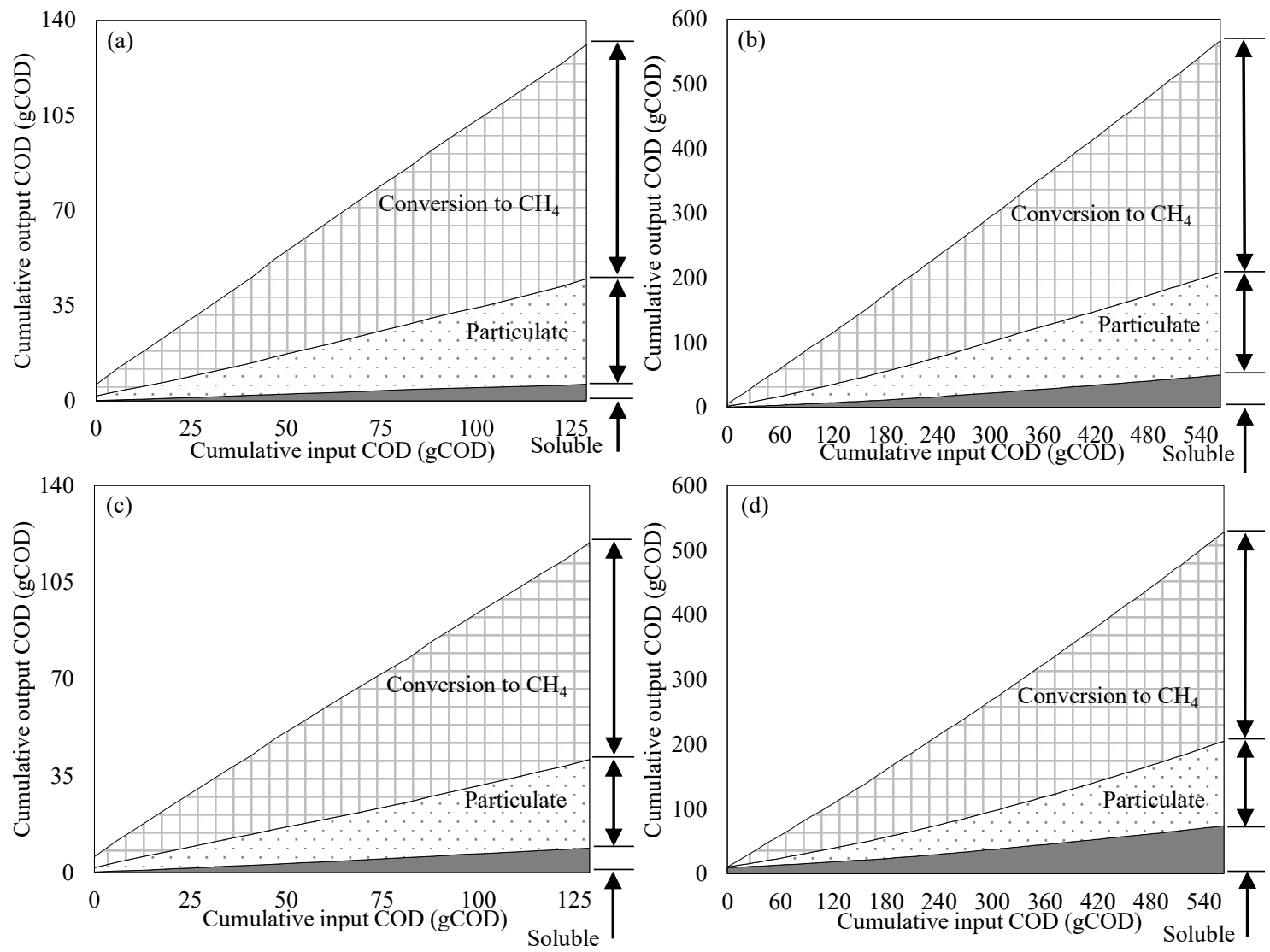

Fig. 4: The COD mass balance breakdown components for (a) chloride reactor at SRT 40 days, (b) chloride reactor at SRT 80 days, (c) bicarbonate reactor at SRT 40 days, and (d) bicarbonate reactor at SRT 80 days. 

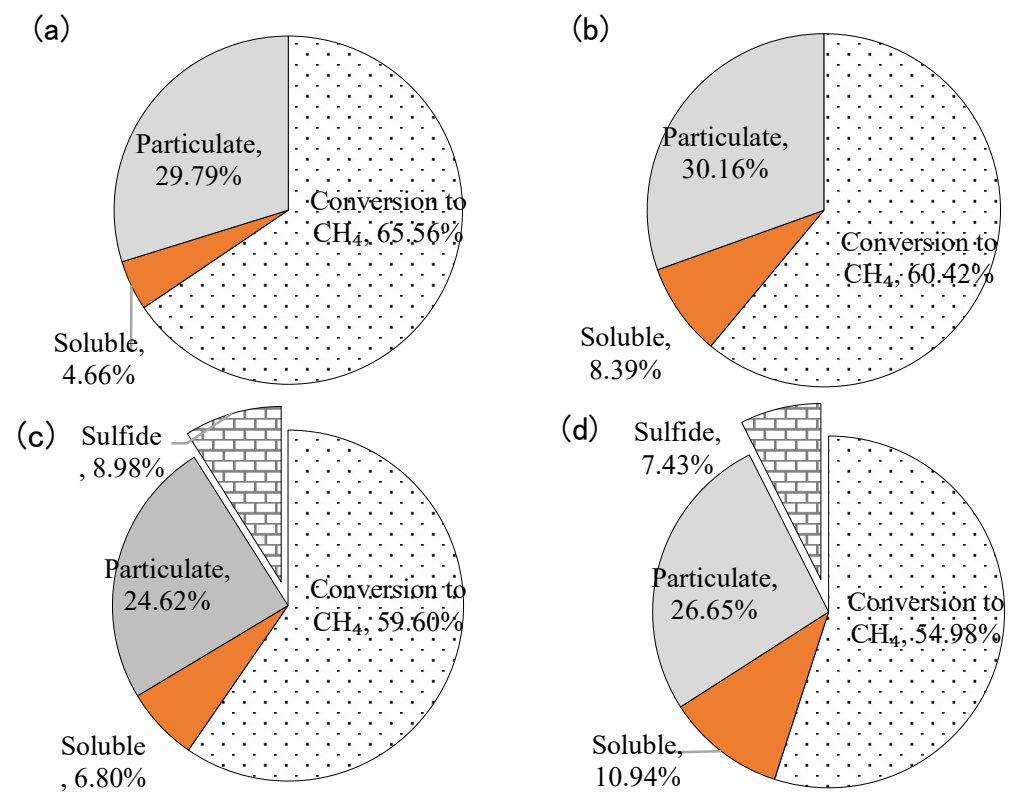

Fig. 5: Conversion rate at steady state for (a) chloride reactor at SRT 40 days, (b) chloride reactor at SRT 80 days, (c) bicarbonate reactor at SRT 40 days, and (d) bicarbonate reactor at SRT 80 days.

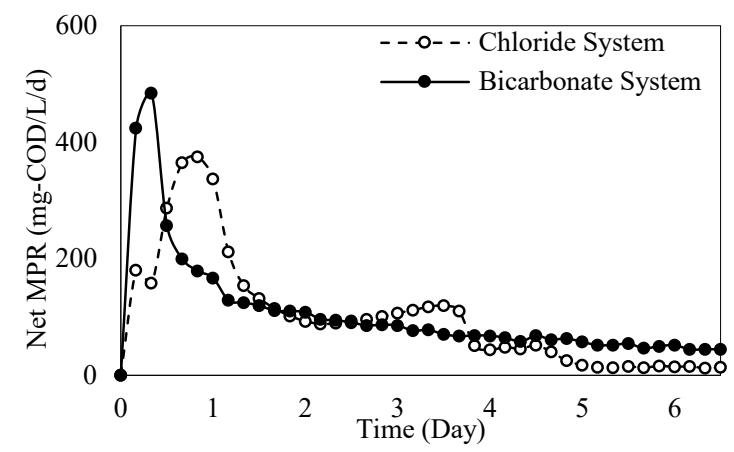

Fig. 6: Methane production rate of undecomposed substrate for chloride and bicarbonate systems.

gas, respectively, as shown in Fig. 5. In contrast, Aslan \& Ekerda (2016) discovered that when saline was fed with $20 \mathrm{~g}-\mathrm{Na}^{+} \cdot \mathrm{L}^{-1}$ in a UASB reactor, COD bioconversion was significantly reduced. Despite the SRT, less than $60 \%$ of input COD was converted to the bicarbonate system, and the remaining fraction of gas was assigned to sulfide as an end product of increased sulfate-reducing bacteria activity. The other components of the particulate fraction were nearly the same as for the chloride system, as well as for a soluble fraction as a small proportion of substrate remained in the digesters.

Therefore, salt-tolerant plant residues harvested from saline-contaminated soil could be disposed of by anaerobic digestion and could be considered as a substrate for methane production. These outcomes offer a promising outlook for future work and may play an important role in future biofuel operations.

\section{Identify the Remaining Amount of Biodegradable Soluble Fractions}

Anaerobic respirometric tests may be able to predict the BMP of substrates because they can detect both easily biodegradable and slowly biodegradable substrates (Argiz et al. 2020). Approx. $80 \%$ soluble fractions were biodegraded as calculated from the BMP experiments results as shown in Fig. 6. Furthermore, the generated methane started immediately and kept increasing until it reached its peak on the first day of the test. Furthermore, methane production was drastically reduced, and after 5 days of digestion, about $90 \%$ of the experimental methane output was obtained. The degradation 
of readily degradable materials in the salt-tolerant biomass caused the MPR curves to the peak.

\section{CONCLUSION}

This study focused on the anaerobic digestion performance under high saline conditions. The results obtained in this study suggested that:

1. Salt-tolerant microorganisms can be incubated and survived under conventional and relatively high SRT because the microorganism was promoted in the system and therefore, improve the phytoremediation plant biodegradation.

2. When compared to the bicarbonate system, the results show that the chloride system produced more methane because the activation of sulfate reduced the microbes in the bicarbonate system.

3. Halophyte biomass would be deemed an effective source of renewable energy generation, notwithstanding the fact that its biodegradability increases at high saline conditions.

\section{ACKNOWLEDGMENT}

The authors are very grateful to the japan society for the promotion of science (JSPS) for the supported the research by grants-in-aid for scientific research, japan \#19h02278 and grant-in-aid for JSPS fellows, japan \#19f19370.

\section{REFERENCES}

APHA. 2005. Standard methods for the examination of water and wastewater. 21 st Edition, American Public Health Association/American Water Works Association/Water Environment Federation, Washington DC.

Argiz, L., Reyes, C., Belmonte, M., Franchi, O., Campo, R., Fra-Vázquez, A. and Campos, J.J.J. 2020. Assessment of a fast method to predict the biochemical methane potential based on biodegradable COD obtained by fractionation respirometric tests. J. Environ. Manag., 269: 110695.
Aslan, S., Şekerdağ, N.J.D. and Treatment, W. 2016. Salt inhibition on anaerobic treatment of high salinity wastewater by upflow anaerobic sludge blanket (UASB) reactor. Desalin.Water Treat., 57(28): 12998-13004.

Chemists, A.O. and Horwitz, W. 1975. Official Methods of Analysis (Vol. 222). Association of Official Analytical Chemists, Washington, DC.

Gallipoli, A., Gianico, A., Gagliano, M. and Braguglia, C.J. 2014. Potential of high-frequency ultrasounds to improve sludge anaerobic conversion and surfactants removal at different food/inoculum ratios. Bioresour. Technol., 159: 207-214.

Kianmehr, P., Mansoor, W. and Kfoury, F.A. 2014. Prediction of biogas generation profiles in wastewater treatment plants using neural networks. J. Clean Energy Technol., 2(3), 201-205.

Lefebvre, O., Quentin, S., Torrijos, M., Godon, J.J., Delgenes, J.P. and Moletta, R.J.A. 2007. Impact of increasing $\mathrm{NaCl}$ concentrations on the performance and community composition of two anaerobic reactors. Appl. Microbiol. Biotechnol., 75(1): 61-69.

Luo, W., Phan, H.V., Hai, F.I., Price, W.E., Guo, W., Ngo, H. H. and Nghiem, L.D.J. 2016. Effects of salinity build-up on the performance and bacterial community structure of a membrane bioreactor. Bioresour. Technol., 200: 305-310.

Margesin, R. and Schinner, F.J.E. 2001. Potential of halotolerant and halophilic microorganisms for biotechnology. Extremophiles, 5(2): 73-83.

Mottet, A., Steyer, J.P., Déléris, S., Vedrenne, F., Chauzy, J. and Carrère, H.J.B. 2009. Kinetics of thermophilic batch anaerobic digestion of thermal hydrolyzed waste activated sludge. Biochem. Eng. J., 46(2): 169-175.

Ras, M., Lardon, L., Bruno, S., Bernet, N. and Steyer, J.P.J. 2011. Experimental study on a coupled process of production and anaerobic digestion of Chlorella vulgaris. Bioresour Technol., 102(1): 200-206.

Segura-Campos, M., Barbosa-Martín, E., Matus-Basto, Á., Cabrera-Amaro, D., Murguía-Olmedo, M., Moguel-Ordo, Y. and Betancur-Ancona, D.J.A. 2014. Comparison of chemical and functional properties of Stevia rebaudiana (Bertoni) varieties cultivated in Mexican Southeast. Amr. J. Plant Sci., 5(3): 286-293.

Sierra, J.D.M., Oosterkamp, M.J., Wang, W., Spanjers, H. and Van Lier, J.B.J. 2018. Impact of long-term salinity exposure in anaerobic membrane bioreactors treating phenolic wastewater: performance robustness and endured microbial community. Front. Bioeng. Biotechnol., 141: 172-184.

Toderich, K., Shuyskaya, E., Ismail, S., Gismatullina, L., Radjabov, T. and Bekchanov, B. 2009. Phytogenic resources of halophytes of Central Asia and their role for rehabilitation of sandy desert degraded rangelands. Land Degrad. Develop., 20(4): 386-396.

Wood, J.M.P. 2015. Bacterial responses to osmotic challenges. J. Gen. Physiol., 145(5): 381-388. 